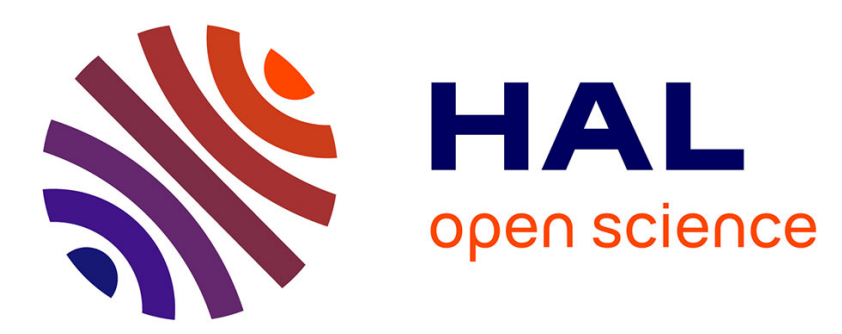

\title{
Impact of Individual Differences on Affective Reactions to Pedagogical Agents Scaffolding
}

Sébastien Lallé, Nicholas V Mudrick, Michelle Taub, Joseph F Grafsgaard, Cristina Conati, Roger Azevedo

\section{- To cite this version:}

Sébastien Lallé, Nicholas V Mudrick, Michelle Taub, Joseph F Grafsgaard, Cristina Conati, et al.. Impact of Individual Differences on Affective Reactions to Pedagogical Agents Scaffolding. International Conference on Intelligent Virtual Agents, Sep 2016, Los Angeles, United States. pp.269-282, 10.1007/978-3-319-47665-0_24. hal-03407422

\section{HAL Id: hal-03407422 \\ https://hal.science/hal-03407422}

Submitted on 28 Oct 2021

HAL is a multi-disciplinary open access archive for the deposit and dissemination of scientific research documents, whether they are published or not. The documents may come from teaching and research institutions in France or abroad, or from public or private research centers.
L'archive ouverte pluridisciplinaire HAL, est destinée au dépôt et à la diffusion de documents scientifiques de niveau recherche, publiés ou non, émanant des établissements d'enseignement et de recherche français ou étrangers, des laboratoires publics ou privés. 


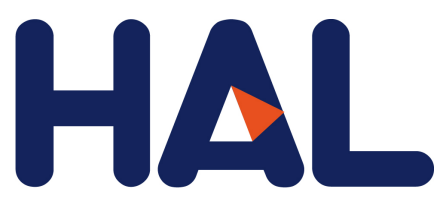

archives-ouvertes

\title{
Impact of Individual Differences on Affective Reactions to Pedagogical Agents Scaffolding
}

\author{
Sébastien Lallé, Nicholas Mudrick, Michelle Taub, Joseph Grafsgaard, \\ Cristina Conati, Roger Azevedo
}

\section{To cite this version:}

Sébastien Lallé, Nicholas Mudrick, Michelle Taub, Joseph Grafsgaard, Cristina Conati, et al.. Impact of Individual Differences on Affective Reactions to Pedagogical Agents Scaffolding. International Conference on Intelligent Virtual Agents, Sep 2016, Los Angeles, United States. pp.269-282, 10.1007/978-3-319-47665-0_24 . hal-03407422

\section{HAL Id: hal-03407422 \\ https://hal.archives-ouvertes.fr/hal-03407422}

Submitted on 28 Oct 2021

HAL is a multi-disciplinary open access archive for the deposit and dissemination of scientific research documents, whether they are published or not. The documents may come from teaching and research institutions in France or abroad, or from public or private research centers.
L'archive ouverte pluridisciplinaire HAL, est destinée au dépôt et à la diffusion de documents scientifiques de niveau recherche, publiés ou non, émanant des établissements d'enseignement et de recherche français ou étrangers, des laboratoires publics ou privés. 


\title{
Impact of Individual Differences on Affective Reactions to Pedagogical Agents Scaffolding
}

\author{
Sébastien Lallé ${ }^{1}$, Nicholas V. Mudrick ${ }^{2}$, Michelle Taub ${ }^{2}$, Joseph F. Grafsgaard ${ }^{2}$, \\ Cristina Conati ${ }^{1}$, and Roger Azevedo ${ }^{2}$ \\ ${ }^{1}$ Department of Computer Science, University of British Columbia, Vancouver, BC, Canada \\ \{lalles, conati\}@cs.ubc.ca \\ ${ }^{2}$ Department of Psychology, North Carolina State University, Raleigh, NC, USA \\ \{nvmudric, mtaub, jfgrafsg, razeved\}@ncsu.edu
}

\begin{abstract}
Students' emotions are known to influence learning and motivation while working with agent-based learning environments (ABLEs). However, there is limited understanding of how Pedagogical Agents (PAs) impact different students' emotions, what those emotions are, and whether this is modulated by students' individual differences (e.g., personality, goal orientation). Such understanding could be used to devise intelligent PAs that can recognize and adapt to students' relevant individual differences in order to enhance their experience with learning environments. In this paper, we investigate the relationship between individual differences and students' affective reactions to four intelligent PAs available in MetaTutor, a hypermedia-based intelligent tutoring system. We show that achievement goals and personality traits can significantly modulate students' affective reactions to the PAs. These findings suggest that students may benefit from personalized PAs that could adapt to their motivational goals and personality.
\end{abstract}

Keywords : Pedagogical agents, Personalization, Emotions, Achievement goals, Personality traits, Intelligent tutoring systems

\section{Introduction}

There is extensive evidence that emotions can impact how well students learn from agent-based learning environments (ABLEs) [1], including how pedagogical agents (PAs) can impact learning and problem-solving through adaptive scaffolding, feedback, and individualized instruction [2,3]. Previous research has investigated how the design (e.g., gender, age, appearance) of PAs influences their effectiveness in fostering learning $[2,4,5]$. Our goal is to extend prior research by examining additional factors (i.e., personality, goal achievement, and emotions) that can impact the effectiveness of PAs in fostering learning with ABLEs. ABLEs include intelligent PAs that are designed to support student learning through tailored prompts, feedback, working examples, etc. However, there is still limited understanding of the reasons for which different emotions occur during interactions with PAs, and what those emotions are. Initial studies showed the influence of students' gender and personality traits on affec- 
tive reactions to PAs [6, 7]. It suggests that further research on the impact of individual differences on student emotions with ABLEs may help researchers gain a more comprehensive understanding of when and how students benefit from PAs in terms of affect, motivation and learning. This understanding, in turn, can be leveraged to devise intelligent PAs that can better adapt to the student's relevant individual differences in order to enhance the student's experience with ABLEs.

In this paper we contribute to this line of research by investigating the relationships of students' achievement goals [8] and personality traits [9] with their affective reactions while learning with MetaTutor, an ABLE that includes four PAs designed to scaffold and foster effective metacognition and self-regulated learning [1]. In particular, we investigate the relationships between achievement goals, personality traits, and students' affective reactions at specific points during the interaction with the system.

The main contributions of this work are as follows. First, our work is the first to examine the impact of students' achievement goals on their affective reactions to PAs. Achievement goals are considered a facet of motivation given that they provide a purpose or focus for the learning task at hand, and, as such, guide students' learning behaviors and performance by setting the standards with which to evaluate success [8]. In general, this framework assumes that students who adopt a mastery-approach goal focus on developing competence and skills, whereas students with a performance-approach goal focus on outperforming their peers [8]. Whereas there is extensive work on the impact of achievement goals on students' performance and motivation in general $[4,10]$, and on student learning while interacting with PAs [11], there are currently no reported studies on the impact of achievement goals specifically on affective reactions to PAs.

Second, we extend recent published findings on the impact of personality traits on student's affective reactions toward MetaTutor. Specifically Harley et al. [7] have shown that personality traits modeled via the five-factor framework [9] can influence emotions retrospectively reported towards PAs at the end of the learning session. In this paper, we extend these results with an analysis of students' emotions reported during interaction with MetaTutor, which provide more fine-grained information on the students' affective reactions when studying with this ABLE.

Lastly, we propose design guidelines about how our results can inform the design of more personalized PA scaffolding and feedback, e.g., promoting more pride to students with a mastery-approach goal by congratulating them when they master new skills. Such personalization could positively impact students' affect and their overall experience when interacting with MetaTutor.

\section{Related Work on Students' Reactions to Pedagogical Agents}

There is extensive evidence that pedagogical agents (PAs) can impact learning, motivation and affect during the interaction with learning environments [2,4]. Further research has shown that students' reaction to such agents can be modulated by student's individual characteristics [12-14]. For instance, achievement goals can impact learning [12] and help-seeking behavior in the presence of PAs [13]. Personality traits 
have been shown to modulate the effect of PAs on learning as well, for instance based on the level of politeness of the agents [14].

Other research has focused more specifically on how individual differences impact the affective reactions of students to PAs $[6,7]$. In particular, personality traits were found to influence the emotions specifically reported towards the agents at the end of the experiment (e.g., "the agent made me feel happy") [7]. For instance, students high in neuroticism reported to feel more bored when interacting with the PA responsible for metacognitive scaffolding. Additionally, students' gender has been shown to impact emotions reported by students during the interaction with PAs depending on the gender of the agent's persona [6].

\section{$3 \quad$ MetaTutor Intelligent Learning Environment}

MetaTutor (Fig. 1) is a hypermedia based intelligent tutoring system with 47 pages of text and diagrams, developed to teach students about the circulatory system and how to self-regulate their learning with the assistance of multiple PAs [1]. When working with MetaTutor, students are given the task of learning as much as they can about the human circulatory system. The main interface of MetaTutor includes a table of contents, a timer that indicates how much time remains in the learning session, and a selfregulated learning (SRL) palette where students can engage in cognitive and metacognitive SRL strategies, with the assistance (i.e., prompts and feedback) of each of four PAs.

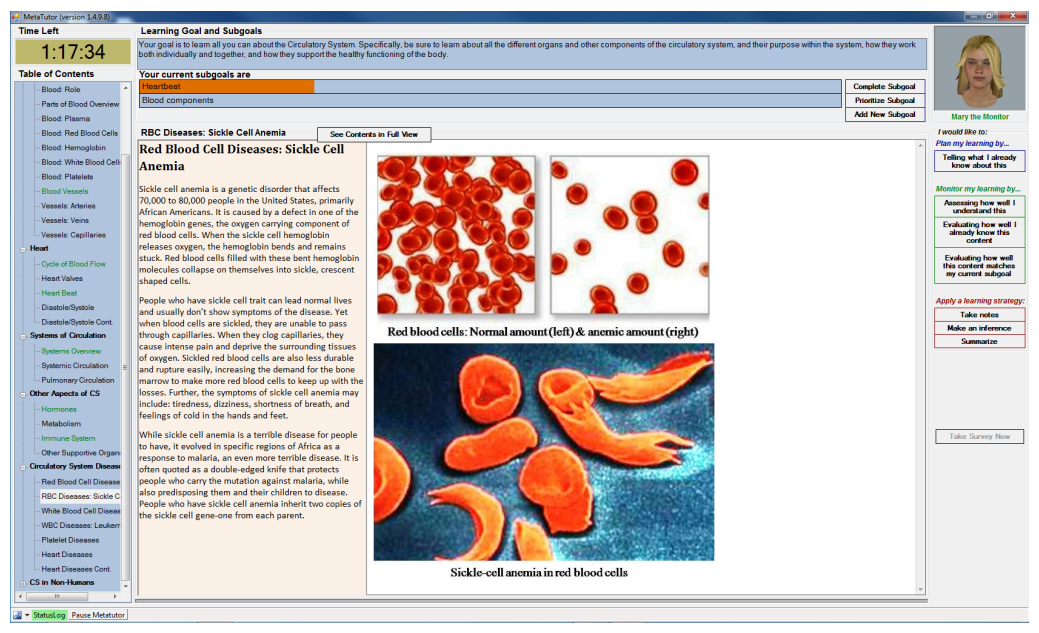

Fig. 1. Screenshot of MetaTutor during the learning session.

Only one PA is displayed at a time in the upper right corner of the screen. Except for Gavin the Guide, each of the PAs is responsible for specific self-regulatory processes and provides audible assistance through the use of a text-to-speech engine. Specifically, Gavin the Guide provides guidance for students in MetaTutor by presenting videos on how to interact with the interface (e.g., how to navigate through the 
content by using the table of contents) and also administers pretest and posttest knowledge assessments and the Emotions and Values (EV) Questionnaire. Pam the Planner prompts and scaffolds planning processes primarily at the beginning of the learning session by assisting the student in creating subgoals relevant to learning as much as they can about the human circulatory system (e.g., path of blood flow, malfunctions of the circulatory system). Mary the Monitor prompts and supports students in their metacognitive monitoring processes (e.g., self-assessment of their progress during learning) that students can use to judge their understanding or relevance of the content to their subgoals. Lastly, Sam the Strategizer prompts students to engage in cognitive learning strategies such as taking notes on the content or summarizing it in their own words.

The PAs are visually rendered using Haptek virtual characters and spoken utterances are produced through Nuance text-to-speech. Haptek animation of the virtual characters includes idle movements when the agents are not speaking (subtle, gradual head and eye movements), as well as lip movements during speech. Nuance text-tospeech provides distinct voices for each of the male and female PAs.

\section{User Study}

The data used for the analysis presented in this paper was collected via a user study during which 62 university students (65\% female, mean age of 19.9) worked with MetaTutor to learn about the circulatory system.

\subsection{Procedure}

The study consisted of two sessions conducted on separate days. During the first session, lasting approximately 30 minutes, students were administered several questionnaires (e.g., demographics, personality questionnaire - cf. section 4.3) and a pretest to assess their knowledge of the circulatory system. During the second session, lasting about three hours, students were first shown an introductory video on MetaTutor, including instructions on how to navigate through the learning environment and use its different components. Next, each student was given 90 minutes to learn as much as possible about the circulatory system using MetaTutor. Students were randomly assigned to work with two different versions of the system, described below. During the session, multi-channel trace data (e.g., eye tracking, log files) were collected to study the cognitive, affective, and metacognitive processes used by students. Additionally, students were asked at various points during the interaction to self-report their current emotions (cf. Section 4.3). Finally, students completed a posttest analogous to the pretest, followed by a series of questionnaires, including a retrospective assessment of how they felt about the PAs (cf. Section 4.3). 


\subsection{Experimental Conditions}

To examine the influence of PAs scaffolding on students' interaction with MetaTutor, students were randomly assigned to either an experimental Prompt and Feedback (PF) condition or Control condition. In the PF condition, the agents proactively provided students with timely prompts to promote the use of SRL strategies, as well as feedback on how students performed these strategies. A set of 20 production rules were used by the PAs to trigger scaffolding based on students' behavior or interaction with the system, such as the time spent on a subgoal or a content page, the relevance of the current page to the active subgoal, changes of page, etc $[1,15]$. For example, if a participant spends a certain amount of time on a page, Mary the Monitor could prompt students to metacognitively judge their understanding of a page, which would lead to a quiz on the information on the page to gauge how accurate their judgment was. Mary would also provide feedback on the results of the quiz, such as suggesting to continue reading the content on that page if less than $70 \%$ of the quiz was correct (i.e., if the participant answered fewer than two out of three questions correctly). Sam the Strategizer could prompt students to summarize the content of the current page if they have been on it for a long time, and Sam would then provide feedback on the students' summary. High-level rules were also implemented to avoid over-prompting, for instance students would not be prompted to summarize the current page if they already refused to do it, but could be prompted to summarize material on the next page. Additionally, students could self-initiate SRL strategies by using the SRL palette and receive feedback on the performance of these strategies as well. For example, students could click on the SRL palette to judge how well they understood the information on the page and would also receive feedback from Mary on their quiz performance.

In the control condition, agents had a much more passive role. They would not prompt the use of any SRL strategies and would not provide any form of feedback on the performance of these strategies. However, students could still self-initiate the use of SRL strategies by clicking on the SRL palette. For example, students would still be able to judge their understanding of the information on the page and would still take a quiz, but they would not get feedback on their performance.

\subsection{Material Collected}

Here we describe the study material that provided the data we leverage to analyze the relationship between achievement goals, personality traits and student emotions.

Achievement goals. The Achievement Goal Questionnaire Revised (AGQ-R) [8] is a 12-item self-report questionnaire that assesses four achievement goal dimensions: (a) mastery-approach, (b) mastery-avoidance, (c) performance-approach, and (d) performance-avoidance. Items were adapted to assess students' motivation for the MetaTutor learning task. Students were asked to indicate the degree to which they agreed with each item using a 7-point Likert scale. A sample item for the masteryapproach subscale is: "my aim is to completely master the material presented during this learning session." A sample item for the performance-approach subscale is: "my 
goal is to perform better than the other student participants." A student's dominant goal is determined based on the highest sub-scale score. In the case of a tie, we assume that the student had no dominant goal and exclude him from the analysis. Following the work of Duffy \& Azevedo [11], we focus only on mastery-approach and performance-approach goals in this work, given that avoidance goals are typically considered less useful to foster effective learning.

Personality traits. The 50-item International Personality Item Pool (IPIP) [16] assesses the personality dimensions of the well-established Five-Factor Model [9], which models personality in terms of: (a) agreeableness (tendency to be more friendly, considerate of others, altruistic, sympathetic), (b) extraversion (associated with high physical and verbal activity, assertiveness, sociability), (c) conscientiousness (associated with efficiency, determination, responsibility, and persistence), (d) neuroticism (tendency to be temperamental and experience negative moods and feelings; e.g., anxiety), and (e) openness (tendency to prefer novel and broader ideas and experiences, intellectual activities, creativity). Students were asked to respond to each IPIP item using a 5-point Likert scale ranging from 1 (very inaccurate) to 5 (very accurate). A sample item is "I get upset easily."

Emotions during interaction. During the interaction with MetaTutor, at regular intervals students had to complete an on-line Emotions and Value (EV) Questionnaire [1]. This questionnaire consists of 15 items, each asking whether the student currently feels one of the 15 emotions listed in Table 3. These items were rated on a 5-point Likert scale ranging from 1 (strongly disagree) to 5 (strongly agree). One example item is: "Right now I feel bored". The instructions and wording of the questions are based on a subscale of the Academic Emotions Questionnaire (AEQ, [17]), that assesses students' current emotions, as opposed to emotions reported on prospective or retrospective measures. The 15 emotions measured using the EV Questionnaire represent a comprehensive list of emotions commonly experienced by students in learning or academic settings [17].

Emotional reactions towards the agents. At the end of the learning session, students were asked to retrospectively assess how they felt about the PAs while they were learning with MetaTutor. To do so, students responded to a questionnaire asking whether each of the 4 PAs made them feel each of the 15 emotions measured by the EV Questionnaire (cf. Table 3), resulting in 4 (agents) $\times 15$ (emotions) $=60$ items. A 5-point Likert scale ranging from 1 (strongly disagree) to 5 (strongly agree) was used for each item. One example item is: "Sam made me feel bored".

\section{$5 \quad$ Statistical Analyses}

In our analyses, we leverage the data collected in the study to investigate whether there is a relationship between achievement goals and personality traits with student affective reactions while working with MetaTutor, and whether the relationship is modulated by the condition in which the agents were used (PF vs. Control). We mainly focus on the emotions reported via the EV Questionnaire during the learning ses- 
sion, but we also integrate results on the emotional reactions reported towards the PAs at the end of the session when they provide more insights on our findings.

Descriptive statistics of the collected personality traits, achievement goals, and emotions reported during the interaction are shown in Tables 1-3. As sadness, hopeless and shame were rarely reported by learners (i.e., Likert scale reports were mostly close to "strongly disagree" for these emotions, resulting in a lack of variance), we removed these emotions from the analysis, resulting in 12 studied emotions.

Table 1. Descriptive statistics for IPIP.

\begin{tabular}{lcc}
\hline Personality traits & M & SD \\
\hline Extraversion & 33.28 & 9.83 \\
Agreeableness & 40.89 & 4.93 \\
Conscientiousness & 36.88 & 6.98 \\
Neuroticism & 28.37 & 7.93 \\
Openness & 38.14 & 5.87 \\
\hline
\end{tabular}

Table 2. Descriptive statistics for AGQ-R.

\begin{tabular}{lcc}
\hline Achievement goals & M & SD \\
\hline Performance-approach & 4.27 & 0.63 \\
Performance-avoidance & 3.6 & 0.82 \\
Mastery-approach & 4.05 & 0.68 \\
Mastery-avoidance & 3.68 & 0.86 \\
\hline
\end{tabular}

Table 3. Descriptive statistics for EV.

\begin{tabular}{lcc|lcc|lcc}
\hline Emotions & M & SD & Emotions & M & SD & Emotions & M & SD \\
\hline Neutral & 3.33 & 1.21 & Pride & 2.57 & 1.13 & Confusion & 1.71 & 0.92 \\
Hope & 3.12 & 1.11 & Anxiety & 2.29 & 1.23 & Eureka & 1.71 & 0.97 \\
Boredom & 2.94 & 1.38 & Frustration & 2.19 & 1.22 & Sadness & 1.40 & 0.73 \\
Curiosity & 2.90 & 1.29 & Surprise & 1.85 & 1.12 & Shame & 1.46 & 0.79 \\
Enjoyment & 2.75 & 1.02 & Contempt & 1.79 & 1.10 & Hopelessness & 1.43 & 0.76 \\
\hline
\end{tabular}

We ran a set of ordinal logistic regressions (appropriate for Likert-scale data [18]), each with one of the reported emotions as the dependent variable, and achievement goals, each of the five personality traits, and the group condition (PF or Control) as the factors. Each factor has 2 levels. For achievement goals, we assigned students in two groups (mastery or performance) based on their dominant goal (i.e., their highest rated goal orientation, as defined Section 4.3). For personality traits, we assigned students to either low or high levels of each trait using a median split. This approach produced 60 models (one for each of the 12 remaining emotions we considered from the EV Questionnaire and one for each of the 48 emotional reactions reported towards the PAs [12 emotions $\times 4$ agents]). Then results were adjusted to account for familywise error using the Holm-Bonferroni approach, which is appropriate to strictly ensure the significance of the statistical effects found when running models on multiple dependent variables. This adjustment was applied based on the number of dependent variables in 5 different families: one for the emotions reported during interaction, and one per set of emotional reactions towards each of the 4 agents. We report statistical significance at the .05 level (using adjusted $p$-values), and effect sizes as small for $r \geq$ 0.1 , medium for $r \geq 0.3$, and large for $r \geq 0.5$. 


\section{Results}

In this section, we first report the significant interactions we found between achievements goals, emotions and experimental condition (Section 6.1), and between personality traits, emotions and experimental conditions (6.2). In Section 6.3, we summarize our findings and discuss their implications.

\subsection{Achievement Goals and Emotions}

We found interaction effects of achievement goals with condition on pride $\left(\chi_{2}(1)=20.5, p<.001, r=.55\right)$, anxiety $\left(\chi_{2}(1)=13.4, p<.001, r=.47\right)$, and pride towards Sam (the agent responsible for prompting cognitive strategies).

The effects on pride (shown in Fig. 2) and anxiety (Fig. 3) follow the same pattern in terms of affective valence, revealing that performance-oriented students experienced more positive affect (more pride, less anxiety) in the PF condition than in the control condition, whereas the effect is reversed for mastery-oriented students (i.e., higher levels of pride and lower levels of anxiety in the control condition). These results are consistent with those for pride towards Sam, which show that performance-oriented students experienced more pride with Sam in the PF condition than in the control condition, with the opposite effect for mastery-oriented students.

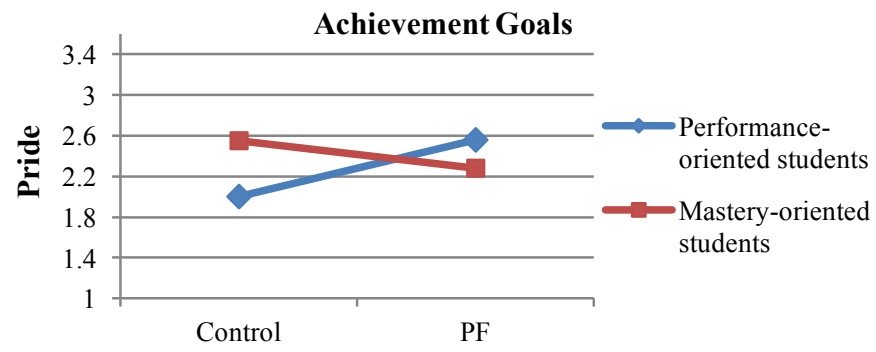

Fig. 2. Interaction effect of achievement goals (performance or mastery goal oriented) with condition on levels of pride reported during interaction.

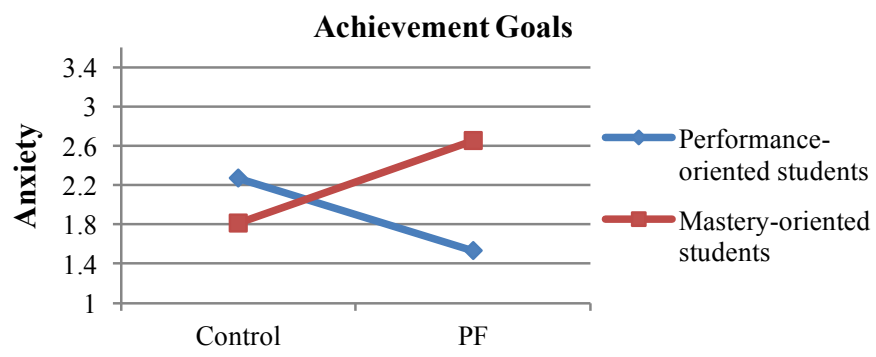

Fig. 3. Interaction effect of achievement goals (performance or mastery goal oriented) with condition on levels of anxiety reported during interaction. 


\subsection{Personality Traits and Emotions}

We found interaction effects of neuroticism, conscientiousness, agreeableness and extroversion with condition on affect.

The interaction effect of neuroticism is on contempt $\left(\chi_{2}(1)=5.4, p=.02, r=.36\right.$ ) (Fig. 4 ), revealing that more neurotic students experienced higher levels of contempt in the PF condition than in the control condition, whereas less neurotic students experienced higher levels of contempt in the control condition.

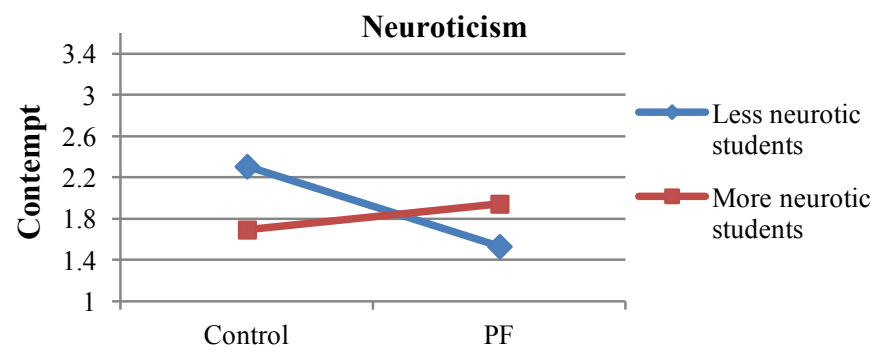

Fig. 4. Interaction effect of neuroticism with condition on levels of contempt reported during interaction.

The interaction effect of conscientiousness is also on contempt $\left(\chi_{2}(1)=17.9, p<.001\right.$, $r=.54$ ) (Fig. 5), showing that more conscientious students experienced lower levels of contempt in the PF condition than in the control condition. There is no effect of conditions for less conscientious students.

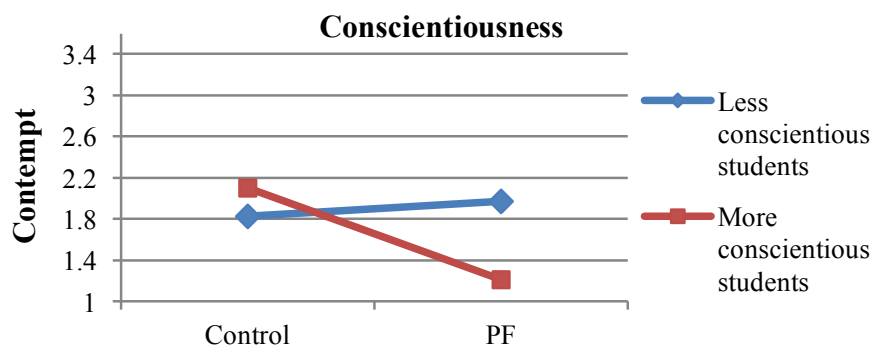

Fig. 5. Interaction effect of conscientiousness with condition on levels of contempt reported during interaction.

The interaction effect of extroversion is on anxiety and anxiety towards Sam $\left(\chi_{2}(1)=4.9, p=.027, r=.28\right)$ (Fig. 6), showing that more extroverted students reported higher levels of anxiety in the PF condition than in the control condition, whereas less extroverted students reported higher levels of anxiety in the control condition. This finding is in part consistent with anxiety towards Sam, showing that more extroverted students experienced more anxiety with Sam in the PF condition than in the control condition (there was no impact of condition for less extroverted students). 


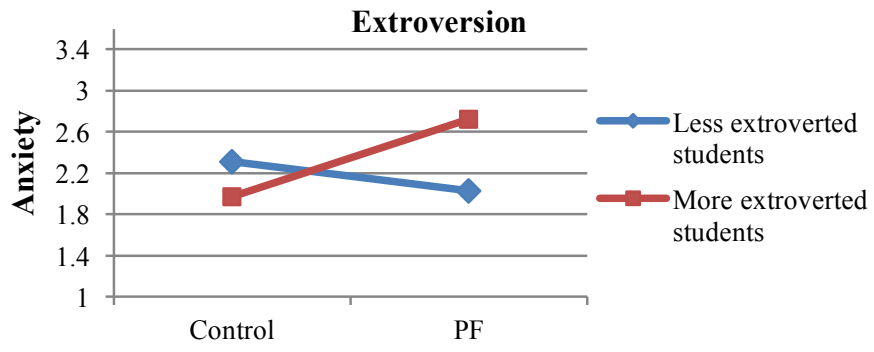

Fig. 6. Interaction effect of extroversion with condition on levels of anxiety reported during interaction.

The interaction effects of agreeableness are on pride $\left(\chi_{2}(1)=14.2, p<.001, r=.48\right)$, curiosity $\left(\chi_{2}(1)=12.5, p=.027, r=.44\right)$, anxiety $\left(\chi_{2}(1)=6.9, p=.009, r=.33\right)$ and contempt $\left(\chi_{2}(1)=10.11, p=.001, r=.41\right)$. The effects on pride (shown Fig. 7) and curiosity (Fig. 8) follow the same pattern, and so do the effects on anxiety (Fig. 9) and contempt (Fig. 10). These effects are not strictly consistent: more agreeable students experienced both positive (more pride and curiosity) and negative affect (more anxiety and contempt) in the PF condition compared to the control condition. As for less agreeable students, there is no effect of condition on pride and curiosity (see Figs. $7 \& 8$ ), but they experienced lower levels of anxiety and contempt (less negative affect) in the PF condition compared to the control condition (see Figs. 9 \& 10).

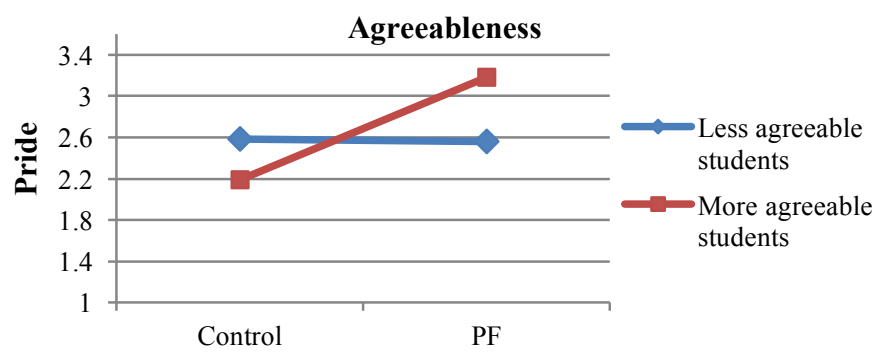

Fig. 7. Interaction effect of agreeableness with condition on levels of pride reported during interaction.

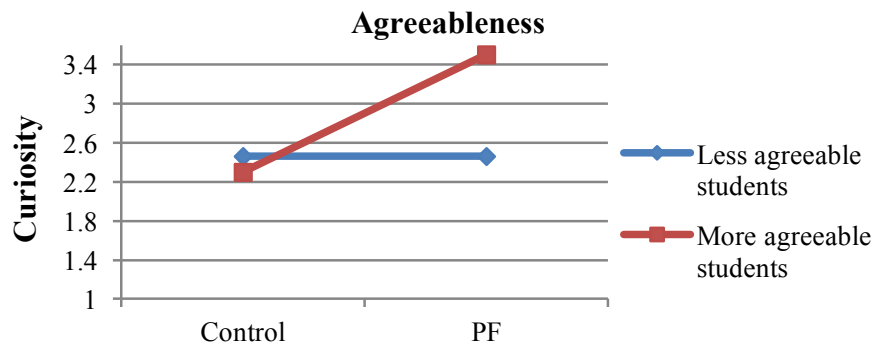

Fig. 8. Interaction effect of agreeableness with condition on levels of curiosity reported during interaction. 


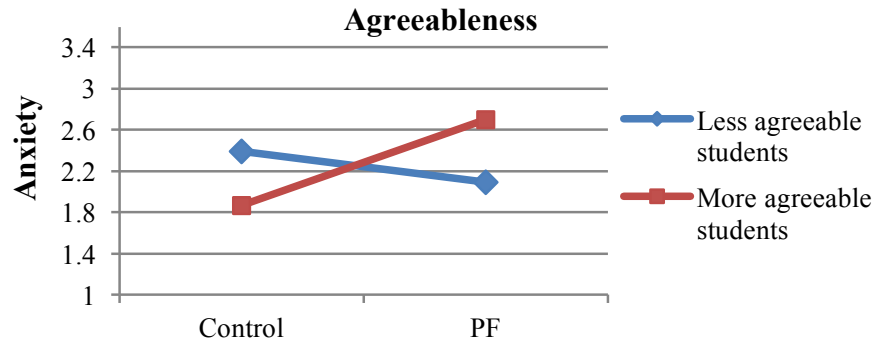

Fig. 9. Interaction effect of agreeableness with condition on levels of anxiety reported during interaction.

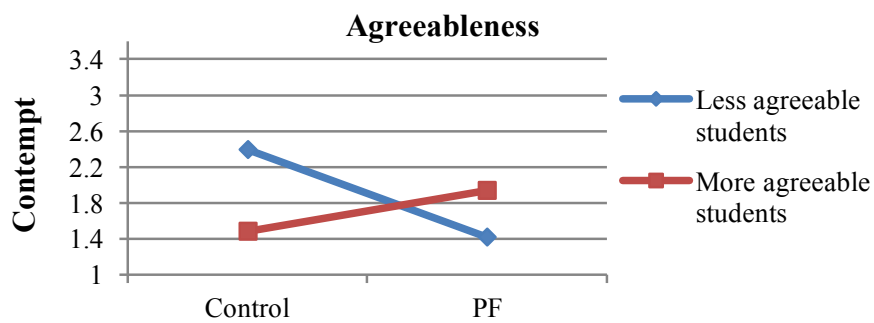

Fig. 10. Interaction effect of agreeableness with condition on levels of contempt reported during interaction.

\subsection{Summary of Findings and Implications for Design of Personalized PAs}

Table 4 summarizes the results reported above in terms of whether MetaTutor agents scaffolding in the PF condition had positive or negative influences on student emotions, for students with different achievement goals and personality traits.

Table 4. Overview of effects found, summarized in terms of the positive or negative impact of prompts and feedback $(\mathrm{PF})$ on affect, modulated by individual differences.

\begin{tabular}{|c|c|c|}
\hline $\begin{array}{l}\text { Individual } \\
\text { differences }\end{array}$ & Positive impact of PF on: & Negative impact of PF on: \\
\hline $\begin{array}{l}\text { Achievement } \\
\quad \text { Goals }\end{array}$ & $\begin{array}{l}\text { - Performance-oriented students (more } \\
\text { pride, less anxiety) }\end{array}$ & $\begin{array}{l}\text { - Mastery oriented students (less pride, more } \\
\text { anxiety) }\end{array}$ \\
\hline Extroversion & - Less extroverted students (less anxiety) & - More extroverted students (more anxiety) \\
\hline Neuroticism & - Less neurotic students (less contempt) & - More neurotic students (more contempt) \\
\hline $\begin{array}{l}\text { Conscien- } \\
\text { tiousness }\end{array}$ & $\begin{array}{l}\text { - Less conscientious students (less con- } \\
\text { tempt) }\end{array}$ & \\
\hline $\begin{array}{l}\text { Agreeable- } \\
\text { ness }\end{array}$ & $\begin{array}{l}\text { - More agreeable students (more pride, } \\
\text { more curiosity) } \\
\text { - Less agreeable students (less anxiety, } \\
\text { less contempt) }\end{array}$ & $\begin{array}{l}\text { - More agreeable students (more anxiety, } \\
\text { more contempt) }\end{array}$ \\
\hline
\end{tabular}

Achievement goals. Our results suggest that achievement goals can play an important role in the emotions responses to the MetaTutor PAs, because they influence how 
students with a more or less proactive role in the interaction react to agents. We found mostly positive impact of agents scaffolding (PF condition) on performance-oriented students, and a negative impact on mastery-oriented students. These results for mastery-oriented students are consistent with previous work showing that those students may not benefit from PAs scaffolding as much as performance-oriented students, in terms of learning $[4,7]$. Possible explanations for these findings include the fact that PAs' proactive interventions may generate a sense of lower perceived autonomy [19] in mastery-oriented students, which is consistent with lower levels of pride and higher levels of anxiety found in our work. In particular, mastery-oriented students reported lower levels of pride with Sam (the PA responsible for cognitive strategies prompting, e.g., taking notes). As Sam provides by far more prompts than any other PAs in MetaTutor, mastery-oriented students may have felt overwhelmed by Sam's scaffolding, resulting in lower perceived autonomy. These findings suggest that masteryoriented students may benefit from personalization of PAs interventions geared toward giving them more autonomy when learning with MetaTutor (e.g., providing fewer prompts, or prompts promoting more active learning). Moreover, empathetic feedback given by the PAs might be improved to promote more pride (e.g., by congratulating them when they achieve their goal and understanding the topic).

Personality traits. Our results (Table 4) indicate that four dimensions of personality, namely agreeableness, extroversion, conscientiousness and neuroticism, can modulate the affective reactions to PAs. These findings are in line with previous work showing that personality traits can impact students' emotional reactions reported towards the PAs [7]. Thus, our results provide further evidence that personality traits may warrant personalized prompts and feedback. In particular, we found that students high in neuroticism, extroversion and agreeableness experienced more negative affect in the PF condition. This might be explained by results from previous work in the field of virtual agents suggesting that users benefit from interacting with agents that match their personality, e.g., [21, 22]. For instance, extroverted students may benefit from more extroverted PAs conveying more social presence [22]; agreeable students may favor more friendly and caring agents [21]. The MetaTutor PAs exhibit no specific personality trait, thus when they have a stronger presence in the PF condition they plausibly are perceived as interfering rather than helping by students with strong personality traits. Thus students may benefit from PAs that can recognize the students' personality and personalize their feedback accordingly, as suggested above. Our results, however, suggest that the need for personalization is not as relevant for conscientiousness, as we found no negative impact in the PF condition for students with either high or low levels of this trait.

\section{Conclusion and Future Work}

We investigated the relationship between individual differences and affective reactions to intelligent pedagogical agents during the interaction with MetaTutor, an agent-based learning environment to foster self-regulated learning and meta- 
cognition. Our objective was to identify individual differences that could be the target of personalized support for improving the user affect provoked by the agents. Overall we found that achievement goals and personality traits do have a significant influence on emotions reported during interaction. Based on these findings, we made several suggestions on how the agents could adapt to the individual differences, for instance by offering more autonomy to mastery-oriented students.

As future work, we first plan to investigate whether achievement goals and personality traits can be detected during the interaction with MetaTutor using students' data collected in real time (e.g., interaction data, eye tracking). Such detection would allow enabling personalization even when it is not viable to assume that students will be able/willing to fill questionnaires. Second, we plan to investigate further how the effects of PAs scaffolding on student affect found in our results are modulated by individual differences, by analyzing student behavior while interacting with the PAs. Finally, we are interested in designing and evaluating the forms of personalization suggested by our results, to examine further whether and how personalized PAs can impact students' affect, motivation and learning.

Acknowledgements. This publication is based upon work supported by the National Science Foundation under Grant No. DRL-1431552 and the Social Sciences and Humanities Research Council of Canada. Any opinions, findings, and conclusions or recommendations expressed in this material are those of the authors and do not necessarily reflect the views of the National Science Foundation or the Social Sciences and Humanities Research Council of Canada.

\section{References}

1. Azevedo, R., Harley, J., Trevors, G., Duffy, M., Feyzi-Behnagh, R., Bouchet, F., Landis, R.: Using trace data to examine the complex roles of cognitive, metacognitive, and emotional self-regulatory processes during learning with multi-agent systems. In: International handbook of metacognition and learning technologies. pp. 427-449. Springer (2013).

2. Schroeder, N.L., Adesope, O.O.: A systematic review of pedagogical agents' persona, motivation, and cognitive load implications for learners. J. Res. Technol. Educ. 46, 229251 (2014).

3. D'Mello, S., Graesser, A.: AutoTutor and affective AutoTutor: Learning by talking with cognitively and emotionally intelligent computers that talk back. ACM Trans. Interact. Intell. Syst. 2, 23 (2012).

4. Heidig, S., Clarebout, G.: Do pedagogical agents make a difference to student motivation and learning? Educ. Res. Rev. 6, 27-54 (2011).

5. Baylor, A.L., Kim, Y.: Pedagogical agent design: The impact of agent realism, gender, ethnicity, and instructional role. In: Intelligent tutoring systems. pp. 592-603. (2004).

6. Arroyo, I., Woolf, B.P., Royer, J.M., Tai, M.: Affective Gendered Learning Companions. In: Proc. of Artificial Intelligence in Education. pp. 41-48. Brighton, U.K. (2009).

7. Harley, J.M., Carter, C.K., Papaionnou, N., Bouchet, F., Landis, R.S., Azevedo, R., Karabachian, L.: Examining the predictive relationship between personality and emotion traits and students' agent-directed emotions: towards emotionally-adaptive agent-based learning environments. User Model. User-Adapt. Interact. 1-43 (2016). 
8. Elliot, A.J., Murayama, K.: On the measurement of achievement goals: Critique, illustration, and application. J. Educ. Psychol. 100, 613 (2008).

9. Costa, P.T., McCrae, R.R.: Four ways five factors are basic. Personal. Individ. Differ. 13, 653-665 (1992).

10. Hidi, S., Harackiewicz, J.M.: Motivating the academically unmotivated: A critical issue for the 21 st century. Rev. Educ. Res. 70, 151-179 (2000).

11. Duffy, M.C., Azevedo, R.: Motivation matters: Interactions between achievement goals and agent scaffolding for self-regulated learning within an intelligent tutoring system. Comput. Hum. Behav. 52, 338-348 (2015).

12. Erhel, S., Jamet, E.: Digital game-based learning: Impact of instructions and feedback on motivation and learning effectiveness. Comput. Educ. 67, 156-167 (2013).

13. Harris, A., Bonnett, V., Luckin, R., Yuill, N., Avramides, K.: Scaffolding effective helpseeking behaviour in mastery and performance oriented learners. In: Proc. of Artificial Intelligence in Education. pp. 425-432. Brighton, U.K. (2009).

14. Wang, N., Johnson, W.L., Mayer, R.E., Rizzo, P., Shaw, E., Collins, H.: The politeness effect: Pedagogical agents and learning outcomes. Int. J. Hum.-Comput. Stud. 66, 98-112 (2008).

15. Azevedo, R., Martin, S.A., Taub, M., Mudrick, N.V., Millar, G.C., Grafsgaard, J.F.: Are Pedagogical Agents' External Regulation Effective in Fostering Learning with Intelligent Tutoring Systems? In: Proc. of Intelligent Tutoring Systems. pp. 197-207. Zagreb, Croatia. Springer (2016).

16. Goldberg, L.R.: A broad-bandwidth, public domain, personality inventory measuring the lower-level facets of several five-factor models. Personal. Psychol. Eur. 7, 7-28 (1999).

17. Pekrun, R., Goetz, T., Frenzel, A.C., Barchfeld, P., Perry, R.P.: Measuring emotions in students' learning and performance: The Achievement Emotions Questionnaire (AEQ). Contemp. Educ. Psychol. 36, 36-48 (2011).

18. Williams, R., others: Generalized ordered logit/partial proportional odds models for ordinal dependent variables. Stata J. 6, 58-82 (2006).

19. Benita, M., Roth, G., Deci, E.L.: When are mastery goals more adaptive? It depends on experiences of autonomy support and autonomy. J. Educ. Psychol. 106, 258 (2014).

20. Carr, A., Luckin, R., Yuill, N., Avramides, K.: How Mastery and Performance Goals Influence Learners' Metacognitive Help-Seeking Behaviours When Using Ecolab II. In: International Handbook of Metacognition and Learning Technologies. pp. 659-668. Springer (2013).

21. Kang, S.-H., Gratch, J., Wang, N., Watt, J.H.: Agreeable people like agreeable virtual humans. In: Proceeding of the International Conference on Intelligent Virtual Agents. pp. 253-261. Springer, Tokyo, Japan (2008).

22. Lee, K.M., Nass, C.: Designing Social Presence of Social Actors in Human Computer Interaction. In: Proceedings of the SIGCHI Conference on Human Factors in Computing Systems. pp. 289-296. ACM, New York, NY, USA (2003). 